\title{
RISK FACTORS AND HEALTH RELATED QUALITY OF LIFE AMONG ADULT PATIENTS OF DEPRESSION PRESENTING AT PSYCHIATRIC OPD CLINIC OF AZIZ FATIMA MEDICAL COLLEGE AND HOSPITAL FAISALABAD.
}

\footnotetext{
1. MBBS, FCPS (Psychiatry) Head Psychiatry and Behavioral Sciences

Aziz Fatima Medical College Faisalabad.

2. MS (Clinical Psychology) M.Phil (Psychology)

Psychiatry OPD Clinic

Aziz Fatima Medical College Faisalabad.

3. MBBS, FCPS (Medicine) Professor Medicine

Aziz Fatima Medical College Faisalabad.
}

Correspondence Address: Dr. Subhan Ullah

Department of Psychiatry and Behavioral Sciences

Aziz Fatima Medical College

Faisalabad

dr.subhan786@hotmail.com

Article received on:

26/03/2020

Accepted for publication:

$27 / 06 / 2020$

\begin{abstract}
Subhan Ullah', Zubash Aslam², Ghulam Abbas Shiekh ${ }^{3}$
ABSTRACT... Objectives: To determine the risk factors of depressive disorders and health related quality of life among adult patients of depression presenting at psychiatric OPD clinic of Aziz Fatima Hospital Faisalabad. Study Design: Cross-sectional study. Setting: Psychiatric OPD clinic of Aziz Fatima Hospital Faisalabad Pakistan. Period: $1^{\text {st }}$ August 2019 to $31^{\text {st }}$ December 2019. Material \& Method: 150 patients for the screening of depression Patient Health Questionnaire (PHQ) was used. For measuring health related quality of life World Health Organization Quality of Life (WHOQOL-Brief) was used. Results: It was found that out of 150 patients with depressive disorder 104(69.3\%) were female and $46(30.7 \%)$ were male patients. Findings of the study assessed that depressive disorder not only impacts on the patients' mood but it also impairs the individuals overall perception of their general health, physical health, psychological wellbeing, social relationship and also distorted perception of their surrounding psychosocial environment. Conclusion: Depressive disorder is common in patients visiting psychiatric OPD clinic and findings of study suggested that age, education level, socio-economic status, death of parent at early age, unemployment, workplace issues, parental separation, loss of partner and family history of depression are important demographic variables which plays the role of significant risk factor for depression and impairs the quality of life among depressive patients.
\end{abstract}

Key words: $\quad$ Depressive Disorder, Quality of Life, World Health Organization.

Article Citation: Subhan Ullah, Aslam Z, Shiekh GA. Risk factors and health related quality of life among adult patients of depression presenting at psychiatric OPD clinic of Aziz Fatima Medical College and Hospital Faisalabad. Professional Med J 2020; 27(9):1976-1982. DOI: 10.29309/TPMJ/2020.27.09.4680

\section{INTRODUCTION}

Depression is one of the most prevalent disorders and it is quite common among developing countries like Pakistan. World Health Organization (WHO) states that globally 350 million individuals suffered from depression. ${ }^{1}$

Depressive disorder is a mood disorder characterized by the persistent presence of low mood, lack of interest and pleasure, reduced self-esteem, hopelessness, and reduced energy, reduced sleep and appetite for at least two weeks. Presence of symptoms for the longer period of time leads to social and professional dyfuOnctioning. ${ }^{2}$ Patients with depressive disorder also experience somatic symptoms that mainly appear as gastrointestinal symptoms, body aches, headache, easily fatigue and generalized weakness in the body. In developing countries like Pakistan different studies conclude that approximately $44.4 \%$ of the population suffered from depression which is higher than other developing countries. ${ }^{3}$

For the general population the likelihood of developing the depression is $5 \%-12 \%$ in males where as in female is $10 \%-25 \%$. Previous studies in Pakistan found different rate of prevalence of depression among three different cities. In the Punjab, Lahore had the highest frequency of depressive disorder which has been estimated around $53.4 \%$ of population of city. ${ }^{4}$

In Pakistan risk factors associated with the increased prevalence of depression among population are being explored. Previous studies indicated that the social factors such as socioeconomic status; education and family 
system are the contributing factors for women in depression. ${ }^{5}$

Growing uncertainty, terrorism, political instability, socio-economic problems, food shortage, global economic slowdown, rising unemployment and other problems are also associated with increased risk of depression in Pakistan. ${ }^{6}$

Quality of life is described as the individual's subjective perception of their overall well-being and impaired quality of life is explained by the difficulties in physical and psychological wellbeing of individuals due to the presence of illness. ${ }^{7}$ As reported by the previous studies quality of life is significantly impaired among the patients of depression and limitations explained by the patients are same as those who suffered with psychical illness. ${ }^{8,9}$ Assessment of a patient's quality of life allows multidimensional evaluation of both the results of treatment and rehabilitation, and the changes in perceived health. Quality of life assessments have in recent years drawn growing interest in contemporary research. In addition to specific symptoms and objectively observable impediments, it is important to estimate the level of subjectively perceived disability in order to obtain an overall view of a patient's functional limitations and to assist him or her to cope with the problems.

The purpose of the present study was to find out the underling risk factor associated with the increase rate of depression among patients presenting to psychiatric OPD clinic of Aziz Fatima Hospital Faisalabad. Further this study aimed to examine the impact of depression on the quality of life among adult patients. In the current circumstances, it is necessary to determine the risk factor associated with depression and its impact on the quality of life of patients so that preventive principles can be developed and Mental Health Professionals can be trained accordingly to deal with such cases to minimize morbidity and improve quality of life among patients.

\section{MATERIAL \& METHODS}

This descriptive cross-sectional study was conducted in the Psychiatric OPD Clinic of
Aziz Fatima Hospital Faisalabad Pakistan for Five months duration from $1^{\text {st }}$ August 2019 to $31^{\text {st }}$ December 2019. The permission about conducting a study and protocols used in the study were approved by the Institutional ethical review committee of hospital. A total sample of 150 patients visiting the psychiatric OPD of hospital was drawn for the purpose of study. Participants were ensured that their information would be kept confidential and they have right to withdraw at any stage of the study. The age range of the patients was 18 to 60 years. For the screening of depressive disorder Urdu version of Patient Health Questionnaire (PHQ) was used. ${ }^{10}$ PHQ-9 being a depression module is not only used as the screening tool for the depression but it is also widely used to evaluate the severity of the depression. PHQ-9 measure the nine criteria symptoms of the DSM-V. ${ }^{10}$ For the assessment of quality of life Urdu version of World Health Organization Quality of Life 26 was used in the present study .WHO-QOL is a 26 -item, self-report measure designed to measure quality of life. ${ }^{11}$ Twenty-four items measure the four doma ins of quality of life: physical, psychological, social, and environmental, and the other two items measure overall quality of life and general health. The score for each question ranges from 1 to 5 , and higher scores reflect higher QOL. For the analysis of data SPSS 22 was used. To find out the strength of a linear association between variables, Pearson Product Moment correlation was used. And for gender differences $t$ test was used in the study.

\section{RESULTS}

A total of 200 patients were screened for depressive disorder. Majority of the patients visiting the psychiatric OPD clinic were female $(n=104,69.3 \%)$. Patients age range was $18-60$ and most of the female patients diagnosed with depression were married $(n=76,50.7 \%)$ while married male $(n=22,14.7)$ ratio was also high. The majority of the patients (70) had primary to secondary level education, 26 respondents were holding bachelor's degrees, whereas 38 patients had master level of education. Amongst the patients $68(45.3 \%)$ were from the joint family system and 82 people belong to nuclear family system. In present study $56 \%$ people belong 
to the low socio-economic system. Out of the total sample of 150 patients, 39(26.0\%) were unemployed, 32(21.3\%) patients were those who lost their parents at an early age, $83(38 \%)$ patients reported with domestic issues, $38(25.3 \%)$ patients were facing issue on their workplace, $16(10.7 \%)$ patients reported parental separation, $27(18.0 \%)$ patients were those who lost their partner, $39(26.0 \%)$ patients with depressive disorder were those who had a family history of depression.

\begin{tabular}{|c|c|c|c|c|}
\hline & & Female & Male & Total (\%) \\
\hline & & $f(\%)$ & $f(\%)$ & \\
\hline \multirow[t]{5}{*}{ Age } & $18-25$ & $35(30.0)$ & $15(10.0)$ & $50(36.67)$ \\
\hline & $25-40$ & $37(24.6)$ & $17(11.3)$ & $54(36.0)$ \\
\hline & $40-50$ & $22(14.6)$ & $3(2.0)$ & $25(16.6)$ \\
\hline & $50-60$ & $10(6.7)$ & $10(6.7)$ & 20(13.3) \\
\hline & Total & $104(69.3)$ & $46(30.7)$ & $150(100.0)$ \\
\hline \multirow[t]{5}{*}{ Education } & Preliterate & $13(8.7)$ & $3(2.0)$ & $16(10.7)$ \\
\hline & Primary-Secondary & $45(30.0)$ & $25(16.7)$ & $70(46.7)$ \\
\hline & Bachelor & $24(16.0)$ & $2(1.3)$ & $26(17.3)$ \\
\hline & Master & $22(14.7)$ & $16(10.7)$ & $38(25.3)$ \\
\hline & Total & 104(69.3) & $46(30.7)$ & $150(100.0)$ \\
\hline \multirow[t]{3}{*}{ Marital Status } & Married & $76(50.7)$ & $22(14.7)$ & $98(65.3)$ \\
\hline & Single & $28(18.7)$ & $24(16.0)$ & $52(34.7)$ \\
\hline & Total & 104(69.3) & $46(30.7)$ & $150(100.0)$ \\
\hline \multirow[t]{3}{*}{ family system } & nuclear & $56(37.3)$ & $26(17.3)$ & $82(54.7)$ \\
\hline & joint & $48(32.0)$ & $20(13.3)$ & $68(45.3)$ \\
\hline & Total & $104(69.3)$ & $46(30.7)$ & $150(100.0)$ \\
\hline \multirow[t]{3}{*}{ Death of Parent at early age } & Yes & $26(17.3)$ & $6(4.0)$ & $32(21.3)$ \\
\hline & No & $78(52.0)$ & $40(26.7)$ & $118(78.7)$ \\
\hline & Total & 104(69.3) & $46(30.7)$ & $150(100.0)$ \\
\hline \multirow[t]{4}{*}{ Socio-economic status } & Low & $59(39.3)$ & $26(17.3)$ & $85(56.7)$ \\
\hline & Middle & $36(24.0)$ & $16(10.7)$ & $52(34.7)$ \\
\hline & High & $9(6.0)$ & $4(2.7)$ & $13(8.7)$ \\
\hline & Total & $104(69.3)$ & $46(30.7)$ & $150(100.0)$ \\
\hline \multirow[t]{3}{*}{ Unemployment } & Yes & $25(16.7)$ & $14(9.3)$ & $39(26.0)$ \\
\hline & No & $79(52.7)$ & $32(21.3)$ & $111(74.0)$ \\
\hline & Total & 104(69.3) & $46(30.7)$ & $150(100.0)$ \\
\hline \multirow[t]{3}{*}{ Workplace- issues } & Yes & $8(5.34)$ & $30(20.0)$ & $38(25.3)$ \\
\hline & No & $85(56.7)$ & $27(18.0)$ & $112(74.7)$ \\
\hline & Total & $104(69.3)$ & $46(30.7)$ & $150(100.0)$ \\
\hline \multirow[t]{3}{*}{ Domestic issues } & Yes & $57(28.0)$ & $26(10.0)$ & $83(38.0)$ \\
\hline & No & $47(31.3)$ & $20(13.3)$ & $67(44.7)$ \\
\hline & Total & $104(69.3)$ & $46(30.7)$ & $150(100.0)$ \\
\hline \multirow[t]{3}{*}{ Parental-separation } & Yes & $14(9.3)$ & $2(1.0)$ & $16(10.7)$ \\
\hline & No & $96(64.0)$ & $38(25.3)$ & 134(89.3) \\
\hline & Total & $104(69.3)$ & $46(30.7)$ & $150(100.0)$ \\
\hline \multirow[t]{3}{*}{ Loss of partner } & Yes & $19(12.7)$ & $8(5.3)$ & $27(18.0)$ \\
\hline & No & $85(56.7)$ & $38(25.3)$ & $123(82.0)$ \\
\hline & Total & $104(69.3)$ & $46(30.7)$ & $150(100.0)$ \\
\hline \multirow[t]{3}{*}{ Family history of illness } & Present & $33(22.0)$ & $6(4.0)$ & $39(26.0)$ \\
\hline & Absent & $71(47.3)$ & $40(26.7)$ & $111(74.0)$ \\
\hline & Total & $104(69.3)$ & $46(30.7)$ & $150(100.0)$ \\
\hline
\end{tabular}

Table-I. Frequency distribution of demographic variables of study $(\mathrm{N}=150)$ 


\begin{tabular}{|c|c|c|c|c|c|}
\hline & 1 & 2 & 3 & 4 & 5 \\
\hline 1. $\mathrm{PHQ}$ & - & & & & \\
\hline 2. Physical Health & $-.47^{\star \star \star}$ & - & & & \\
\hline 3. Psychological & $-.44^{\star \star \star}$ & $.84^{\star \star \star}$ & - & & \\
\hline 4.Social Relationship & $-.21^{* *}$ & $.55^{\star \star \star}$ & $.52^{\star \star \star}$ & - & \\
\hline 5. Environment & $-.31 * * *$ & $.59 * * *$ & $.56^{* * *}$ & $.40^{* * *}$ & - \\
\hline
\end{tabular}

\begin{tabular}{|c|c|c|c|c|c|c|c|}
\hline & \multicolumn{2}{|c|}{ Gender } & \multirow[b]{2}{*}{ df } & \multirow[b]{2}{*}{$t$} & \multirow{2}{*}{$\begin{array}{c}95 \% \mathrm{Cl} \\
\mathrm{LL}\end{array}$} & \multirow[b]{2}{*}{ UL } & \multirow[t]{2}{*}{ Cohen's d } \\
\hline & Male & Female & & & & & \\
\hline Variables & $M(S D)$ & $M(S D)$ & & & & & \\
\hline $\mathrm{PHQ}$ & $15.00(5.88)$ & $18.44(6.99)$ & 148 & $3.101 * *$ & 1.24 & 5.64 & 0.532 \\
\hline WHOQOL & 72.95(19.71) & $54.32(15.86)$ & 148 & $5.60 * * *$ & 25.25 & 11.99 & 1 \\
\hline
\end{tabular}

\begin{tabular}{|c|c|c|c|c|c|c|c|}
\hline & Gender & & & & $95 \% \mathrm{Cl}$ & & Cohen's d \\
\hline & Male & Female & & & & & \\
\hline Variables & $M(S D)$ & $M(S D)$ & df & $\mathrm{t}$ & LL & UL & \\
\hline Physical-health & $10.95(3.07)$ & $7.53(2.62)$ & 148 & $6.55^{\star * \star}$ & 4.45 & 2.37 & 1.19 \\
\hline Psychological & 10.94(3.03) & $8.60(2.76)$ & 148 & $4.46 * * \star$ & 3.38 & 1.29 & 0.80 \\
\hline Social-relationship & $11.10(4.20)$ & $8.41(5.15)$ & 148 & 148 & 4.27 & 1.10 & 0.57 \\
\hline Environment & $11.42(4.40)$ & $9.02(2.91 i)$ & 148 & $3.67^{\star \star}$ & 3.81 & .977 & 0.64 \\
\hline
\end{tabular}

\begin{tabular}{|c|c|c|c|}
\hline & \multicolumn{2}{|c|}{ Gender } & \multirow[b]{2}{*}{ Total } \\
\hline & Female & Male & \\
\hline Infertility & 6 & 4 & 10 \\
\hline Diabetes & 5 & 7 & 12 \\
\hline Hypertension & 7 & 5 & 12 \\
\hline Asthma & 2 & 1 & 3 \\
\hline COPD & 2 & 0 & 2 \\
\hline $\mathrm{BPH}$ & 1 & 0 & 1 \\
\hline Stroke & 5 & 0 & 5 \\
\hline Chronic hepatitis C & 4 & 1 & 5 \\
\hline Cardiovascular disease & 2 & 3 & 5 \\
\hline
\end{tabular}

\begin{tabular}{|l|c|c|c|}
\hline & \multicolumn{2}{|c|}{ Gender } & Total \\
\hline Minimal & Male & Female & 09 \\
\hline Mild & 7 & 2 & 11 \\
\hline Moderate & 8 & 3 & 35 \\
\hline Moderate severe & 13 & 22 & 54 \\
\hline Severe & 21 & 33 & 41 \\
\hline
\end{tabular}




\section{DISCUSSION}

Depression is a highly prevalent disorder that can affect individuals with any age, ethnicity, gender, and people of every walk of life. The present study identifies the risk factors associated with diagnosis of depressive disorder and its impact on the quality of life in a private tertiary care hospital Faisalabad, Pakistan. The results of the researches indicated that depression is more common psychiatric disorder among women and female working as housewives subjected to domestic pressures were more prone to develop depression. ${ }^{12}$ Our study also found that the education level of the patients was associated with prevalence of depression. In the present study, the majority of the patients were not highly educated which contributed to the severity of their illness. Results of the previous studies indicated that the prevalence of depression is less in people with the high level of education. ${ }^{13}$ Results of the our study also suggested that the death of a patient's parent at an early age was also associated with depressive symptoms since early age. ${ }^{14}$ In developing countries like Pakistan socioeconomic status of the patients also play a significant role in the outcome of depression symptoms.

The study also found an association of depressive symptoms and socioeconomic status of patients. Patient with low socioeconomic status was more prone to depression because of their financial burden and in Pakistan most of the people living in joint families have to take financial responsibilities of their family alone. Previous studies also reported the low level of socioeconomic status is related to the high risk of depression. ${ }^{15,16}$ Findings of the present study also suggested that unemployment among young male and female was also associated with depressive symptoms in our society which is also consistent with the other studies. Studies found that people who are unemployed had twice the risk of depressive disorder as compared to those who are employed. ${ }^{17,18}$

In male patients who are employed our findings of the study showed that issue relating to their job stress such as long working hours and lack of incentives was associated with the risk of depression. ${ }^{19}$ In the young patients' parental separation was found as a risk factor for the outcome of the depressive disorder. Previous studies also reported the parental separation increase the risk of depressive disorder among young adults. ${ }^{20,21}$ Patients who had experienced the loss of their partner also reported significant high level of depression. Studies reported that minor level of the depression roots from the reaction to the stressors of life. ${ }^{22}$ In our study family history of patients with psychiatric illness also play a significant risk factor in their diagnosis of depression. ${ }^{23}$ Present study also highlighted the gender differences in the outcome of depression. Previous studies also explained the high rate of depression prevalence among women. ${ }^{24}$

Our studies indicated that among the depressive patients quality of life is significantly impaired. This impairment was observed in all domains of quality of life of patients. Findings of the study assessed that depressive disorder not only impacts on the patients' mood but it also impairs the individuals overall perception of their health, physical health, psychological wellbeing, social relationship and also distorted their perception of their surrounding environment. Our findings are in line with previous studies which also reported that depression deteriorated the physical health of the patients and the severity of depression significantly impairs the quality of life among patients. ${ }^{25}$

We also found the bodily pain, headache and hindrance in physical functioning also impair their general health perception. In female patient's physical health, psychological well-being, social relationship and their perception about their environment is significantly impaired. In the patient with a severe level of depression, their perception of their physical health is highly distorted due to which patient experience themselves as being physically ill. Studies suggested that this is very important in general practice because patients with severe depression complain about somatic symptoms to the general physicians. ${ }^{25}$

In present study depression is also associated 
with other medical conditions among patients. Previous studies suggested that in primary care depression often co-morbid with other medical condition and one-third to half of these cases are not properly diagnosed with depression. Such as infertility being a distressful experience for people it also impact the psychological wellbeing of patients and depression is one of the mental disorder that significantly affect the quality of life among these patients. ${ }^{26}$ It was also found out that depression also contribute to the high risk of diabetes. ${ }^{27}$ In other medical conditions such as asthma, hypertension, Benign Prostatic Hyperplasia, Chronic Obstructive Pulmonary Disease, stroke and chronic hepatitis depression is potential risk factor that significantly impacts the mental well-being of patients and their followup with treatment. ${ }^{28,29,30,31,32}$

\section{DECLARATIONS}

Conflicts of Interest: The authors declared no potential conflicts of interest with respect to the research, authorship, and/or publication of this article.

Copyright@ 27 June, 2020.

\section{REFERENCES}

1. World Health Organization. (2002). The world health report 2002: Reducing risks, promoting healthy life. World Health Organization.

2. Selwyn CN, Schneider M, Anderson C, LanghinrichsenRohling J. Recognizing the hurt: Prevalence and correlates of elevated PTSD symptoms among adolescents receiving mental/behavioral health services in primary care. Psychological services. 2019 Feb;16(1):58.

3. Husain N, Creed F, Tomenson B. Depression and social stress in Pakistan. Psychological medicine. 2000 Mar;30(2):395-402.

4. Gadit AA, Mugford G. Prevalence of depression among households in three capital cities of Pakistan: need to revise the mental health policy. Plos one. 2007 Feb 14;2(2):e209.

5. Fernández-Rodríguez C, González-Fernández S, Coto-Lesmes R, Pedrosa I. Behavioral Activation and Acceptance and Commitment Therapy in the Treatment of Anxiety and Depression in Cancer Survivors: A Randomized Clinical Trial. Behavior Modification. 2020 Apr 21:0145445520916441.
6. Mumford DB, Saeed K, Ahmad I, Latif S, Mubbashar $\mathrm{MH}$. Stress and psychiatric disorder in rural Punjab. British Journal of Psychiatry. 1997;170(5):473-8.

7. Tengland PA. The goals of health work: Quality of life, health and welfare. Medicine, Health Care and Philosophy. 2006 Jul 1;9(2):155-67.

8. Wells KB, Stewart A, Hays RD, Burnam MA, Rogers W, Daniels M, Berry S, Greenfield S, Ware J. The functioning and well-being of depressed patients: results from the Medical Outcomes Study. Jama. 1989 Aug 18;262(7):914-9.

9. Hays RD, Wells KB, Sherbourne CD, Rogers W, Spritzer $\mathrm{K}$. Functioning and well-being outcomes of patients with depression compared with chronic general medical illnesses. Archives of general psychiatry. 1995 Jan 1;52(1):11-9.

10. Ahmad S, Hussain S, AkhtarF, Shah FS. Urdu translation and validation of PHQ-9, a reliable identification, severity and treatment outcome tool for depression. J Pak Med Assoc. 2018 Aug 1;68:1166-70.

11. Lodhi FS, Raza O, Montazeri A, Nedjat S, Yaseri M, Holakouie-Naieni K. Psychometric properties of the Urdu version of the World Health Organization's quality of life questionnaire (WHOQOL-BREF). Medical journal of the Islamic Republic of Iran. 2017;31:129.

12. Drenkard C, Bao G, Lewis TT, Pobiner B, Priest J, Lim SS. Physician-patient interactions in African American patients with systemic lupus erythematosus: Demographic characteristics and relationship with disease activity and depression. InSeminars in arthritis and rheumatism 2019 Feb 1 (Vol. 48, No. 4, pp. 669-677). WB Saunders.

13. Scarinci IC, Beech BM, Naumann W, Kovach KW, Pugh L, Fapohunda B. Depression, socioeconomic status, age, and marital status in black women: a national study. Ethnicity \& disease. 2002;12(3):421.

14. Birtchnell J. Depression in relation to early and recent parent death. The British Journal of Psychiatry. 1970 Mar;116(532):299-306.

15. Everson SA, Maty SC, Lynch JW, Kaplan GA. Epidemiologic evidence for the relation between socioeconomic status and depression, obesity, and diabetes. Journal of psychosomatic research. 2002 Oct $1 ; 53(4): 891-5$.

16. Gilman SE, Kawachi I, Fitzmaurice GM, Buka SL. Socioeconomic status in childhood and the lifetime risk of major depression. International journal of epidemiology. 2002 Apr 1;31(2):359-67. 
17. Dooley D, Catalano R, Wilson G. Depression and unemployment: panelfindings from the Epidemiologic Catchment Area study. American journal of community psychology. 1994 Dec 1;22(6):745-65.

18. Lerner D, Adler DA, Chang H, Lapitsky L, Hood MY, Perissinotto C, Reed J, McLaughlin TJ, Berndt ER, Rogers WH. Unemployment, job retention, and productivity loss among employees with depression. Psychiatric Services. 2004 Dec;55(12):1371-8.

19. Mascha C, Koeter MW, Bockting CL, Schene $A H$, DELTA Study Group. Health related quality of life in recurrent depression: a comparison with a general population sample. Journal of Affective Disorders. 2010 Jan 1;120(1-3):126-32.

20. Takeuchi H, Hiroe T, Kanai T, Morinobu S, Kitamura T, Takahashi K, Furukawa TA. Childhood parental separation experiences and depressive symptomatology in acute major depression. Psychiatry and Clinical Neurosciences. 2003 Apr;57(2):215-9.

21. Roy A. Early parental separation and adult depression. Archives of General Psychiatry. 1985 Oct $1 ; 42(10): 987-91$.

22. Beekman AT, Deeg DJ, van Tilburg T, Smit JH, Hooijer C, van Tilburg W. Major and minor depression in later life: a study of prevalence and risk factors. Journal of affective disorders. 1995 Dec 24;36(1-2):65-75.

23. Kupfer DJ, Frank E, Carpenter LL, Neiswanger K. Family history in recurrent depression. Journal of Affective Disorders. 1989 Sep 1;17(2):113-9.

24. Angst J, Gamma A, Gastpar M, Lépine JP, Mendlewicz J, Tylee A. Gender differences in depression. European archives of psychiatry and clinical neuroscience. 2002 Oct 1;252(5):201-9.
25. Saarijärvi S, Salminen JK, Toikka T, Raitasalo R. Healthrelated quality of life among patients with major depression. Nordic journal of psychiatry. 2002 Jan $1 ; 56(4): 261-4$

26. Al-Homaidan HT. Depression among women with primary infertility attending an infertility clinic in Riyadh, Kingdom of Saudi Arabia: rate, severity, and contributing factors. International journal of health sciences. 2011 Jul;5(2):108.

27. Mezuk B, Eaton WW, Albrecht S, Golden SH. Depression and type 2 diabetes over the lifespan: a meta-analysis. Diabetes care. 2008 Dec 1;31(12):238390.

28. Carson AJ, MacHale S, Allen K, Lawrie SM, Dennis M, House A, Sharpe M. Depression after stroke and lesion location: a systematic review. The Lancet. 2000 Jul 8;356(9224):122-6.

29. Norwood R. Prevalence and impact of depression in chronic obstructive pulmonary disease patients. Current opinion in pulmonary medicine. 2006 Mar $1 ; 12(2): 113-7$.

30. Qureshi MO, Khokhar N, Shafqat F. Severity of depression in hepatitis $\mathbf{B}$ and hepatitis $\mathbf{C}$ patients. $\mathbf{J}$ Coll Physicians Surg Pak. 2012 Oct 1;22(10):632-4.

31. Scalco AZ, Scalco MZ, Azul JB, Lotufo Neto F. Hypertension and depression. Clinics. 2005 Jun;60(3):241-50.

32. Zakaria L, Anastasiadis AG, Shabsigh R. Common conditions of the aging male: erectile dysfunction, benign prostatic hyperplasia, cardiovascular disease and depression. International urology and nephrology. 2001 Jun 1;33(2):283-92.

\begin{tabular}{|c|l|l|l|}
\hline \multicolumn{3}{|c|}{ AUTHORSHIP AND CONTRIBUTION DECLARATION } \\
\hline Sr. \# & \multicolumn{1}{|c|}{ Author(s) Full Name } & Contribution to the paper & Author(s) Signature \\
\hline 1 & Subhan Ullah & 1st Author & \\
\hline 2 & Zubash Aslam & 2nd Author & \\
\hline 3 & Ghulam Abbas Shiekh & 3rd Author & \\
\hline
\end{tabular}

